\title{
Comparison between conjugated linoleic acid and essential fatty acids in preventing oxidative stress in bovine mammary epithelial cells
}

\author{
L. Basiricò, ${ }^{*}$ P. Morera, ${ }^{*}$ D. Dipasquale, ${ }^{*}$ A. Tröscher,† and U. Bernabucci ${ }^{* 1}$ \\ *Dipartimento di Scienze e Agrarie e Forestali (DAFNE), Università degli Studi della Tuscia, via S. Camillo De Lellis, s.n.c, 01100 Viterbo, Italy \\ †BASF-SE, 67117 Ludwigshafen, Germany
}

\section{ABSTRACT}

Some in vitro and in vivo studies have demonstrated protective effects of conjugated linoleic acid (CLA) isomers against oxidative stress and lipid peroxidation. However, only a few and conflicting studies have been conducted showing the antioxidant potential of essential fatty acids. The objectives of the study were to compare the effects of CLA to other essential fatty acids on the thiol redox status of bovine mammary epithelia cells (BME-UV1) and their protective role against oxidative damage on the mammary gland by an in vitro study. The BME-UV1 cells were treated with complete medium containing $50 \mu \mathrm{M}$ of cis-9,trans-11 CLA, trans-10,cis-12 CLA, $\alpha$-linolenic acid, $\gamma$-linolenic acid, and linoleic acid. To assess the cellular antioxidant response, glutathione, NADPH, and $\gamma$-glutamyl-cysteine ligase activity were measured $48 \mathrm{~h}$ after addition of fatty acids (FA). Intracellular reactive oxygen species and malondialdehyde production were also assessed in cells supplemented with FA. Reactive oxygen species production after $3 \mathrm{~h}$ of $\mathrm{H}_{2} \mathrm{O}_{2}$ exposure was assessed to evaluate and to compare the potential protection of different FA against $\mathrm{H}_{2} \mathrm{O}_{2}$-induced oxidative stress. All FA treatments induced an intracellular GSH increase, matched by high concentrations of NADPH and an increase of $\gamma$-glutamyl-cysteine ligase activity. Cells supplemented with FA showed a reduction in intracellular malondialdehyde levels. In particular, CLA isomers and linoleic acid supplementation showed a better antioxidant cellular response against oxidative damage induced by $\mathrm{H}_{2} \mathrm{O}_{2}$ compared with other FA.

Key words: conjugated linoleic acid, essential fatty acids, oxidative status, bovine mammary cells

\section{INTRODUCTION}

Lipids contained in dietary fat are known to be an excellent source of energy, and studies undertaken in

Received July 12, 2016.

Accepted November 19, 2016.

${ }^{1}$ Corresponding author: bernab@unitus.it the first quarter of the 20th century demonstrated that they were necessary for growth and normal physiological function (Spector and Kim, 2015). In recent years, interest has grown in the health properties of functional fatty acids, such as long-chain n-3 and n-6 fatty acids and CLA, because of their biological roles in cells (Bauman and Lock, 2006; Lunn and Theobald, 2006). Omega-6 and n-3 fatty acids are regarded as essential fatty acids (EFA) because mammals cannot synthesize them and they must be obtained from diet. Essential fatty acids form an important constituent of all cell membranes and confer to membranes properties of fluidity, thus determining and influencing the behavior of membrane-bound enzymes and receptors (Das, 2006). Among n-6 fatty acids, linoleic acid $(\operatorname{LnA} ; 18: 2 \mathrm{n}-6)$ is the most common $n-6$ PUFA, whereas $\alpha$-linoleic acid ( $\operatorname{aLnA}$ ), belonging to cis n-3 PUFA, is the most prevalent n-3 fatty acid. Linoleic acid is often found in nature and is present in the seeds of most plants, except for coconut, cocoa, and palm. $\alpha$-Linoleic acid, on the other hand, is found in the chloroplasts of green leafy vegetables and in the seeds of flax, rape, chia, perilla, and in walnuts (Lunn and Theobald, 2006; Simopoulos, 2008). It is from these 2 parent EFA that the n-3 and n- 6 fatty acid families are derived through a series of enzyme-catalyzed desaturation and elongation reactions, which generally take place in the cell cytosol or in the mitochondria. $\alpha$-Linoleic acid is metabolized to docosahexaenoic acid (22:6n-3) via eicosapentaenoic acid (EPA; 20:5n-3) and docosapentaenoic acid (22:5n3 ), whereas LnA is metabolized to arachidonic acid (ArA; 20:4n-6) via $\gamma$-linolenic acid (gLnA; 18:3n-6) or eicosadienoic acid (20:2n-6), as 2 pathways are active (Lunn and Theobald, 2006). Arachidonic acid, the derivative of $\mathrm{LnA}$, can be converted into the 2-series of thromboxanes and the 4-series of leukotrienes. These are very important, active, and short-lived hormones termed eicosanoids, which are involved in various patho-physiological processes concerning inflammatory conditions such as atherosclerosis, obesity, and inflammatory bowel disease. In contrast, the aLnA derivate, such as EPA, gives rise to an entirely different set of eicosanoids. These are the 3 -series prostaglandins and 
thromboxanes and the 5-series leukotrienes, which are considered to be less inflammatory or even anti-inflammatory in comparison to the eicosanoid family derived from ArA (Patterson et al., 2012).

In dairy cows, it has been observed that dietary LnA and aLnA supplementation can be a nutritional strategy to improve reproductive performance and increase the percentage of pregnancies in lactating cows (Dirandeh et al., 2013). This is because EFA can stimulate the follicular growth and steroid production (Leroy et al., 2013). Furthermore, LnA and aLnA are able to modulate the inflammation and the immune response in dairy cows (Lessard et al., 2003; Caldari-Torres et al., 2011).

Conjugated linoleic acids are a group of constitution and conformation isomers of $\mathrm{LnA}$ that are formed in the course of biohydrogenation in the rumen and later endogenous conversion from vaccenic acid (Schmid et al., 2006; Bauman et al., 2008). The isomers that contain a double bond in the trans configuration are biologically active. The most studied bioactive CLA are the cis9,trans-11 isomer and the trans-10,cis-12 isomer. The role of CLA on health has been investigated in animal and human studies (Pires and Grummer 2008; Mele et al., 2013). It was observed that CLA might play an important protective role in cancer, cardiovascular diseases, obesity, osteoporosis, and in immune and inflammatory responses (Benjamin and Spener, 2009; Moraes et al., 2012; Oliveira et al., 2012; Du et al., 2014).

Ruminants have evolved to feed on fresh grass and leaves. According to their feed preferences, Hofmann and Stewart (1972) classified them as concentrate selectors, intermediate-mixed feeders, or grass and roughage eaters. The dairy cow belongs to the group of grazer or roughage eaters, such as Bos primigenius (aurochs), relying on grasses and roughage. Modern TMR diets differ significantly from the natural diet of a cow (e.g., in its ruminal production of CLA). Elgersma et al. (2004) showed that milk from cows feeding on fresh grass quickly decreases in CLA when the diet was changed to the more modern silage or concentrate TMR type. In a review, Elgersma et al. (2006) concluded, in general, that cows on fresh grass (e.g., pasture) produce milk with a significant higher level of CLA. This observed difference in CLA content in milk triggered extensive research into increasing CLA levels in milk from TMR-fed cows, with the focus being on human health. However, these studies (Elgersma et al., 2004, 2006) triggered only limited interest considering CLA as a nutrient and the wellbeing of the cow in the first place. Studies on farm animals showed that some CLA isomers decrease milk fat synthesis, and may thus improve energy balance and alleviate energy demands in lactating dairy cattle. It has been routinely observed that CLA reduce milk fat percentage, increase milk yield, improve reproduction in early lactation, reduce incidence of metabolic disorders during early lactation (ketosis), and reduce negative effects of inflammatory processes during the periparturient period (Bauman et al., 2008; Galamb et al., 2016). Some studies have shown the protective effects of CLA isomers against oxidative stress and lipid peroxidation in animal models (Andreoli et al., 2010; Chinnadurai et al., 2013). Gessner et al. (2015) in cows, and in dairy ewes, Zeitz et al. (2015) demonstrated significantly higher vitamin E and A concentrations in milk from CLA-supplemented animals. Changes in the oxidative metabolism occur in the transition period of dairy cows, and several studies have suggested that oxidative stress increases the susceptibility of dairy cattle to diseases (Bernabucci et al., 2005; Castillo et al., 2005; Sordillo and Aitken, 2009). Nevertheless, results regarding the effects of supplementing antioxidants (vitamins and trace elements) on dairy cow health and performance have been inconsistent, because, in most cases, the antioxidant potential of the animals was not assessed beforehand and the nutritional strategies were not planned accordingly (Abuelo et al., 2015). Therefore, reviewing the redox balance in dairy cattle could help establish new nutritional strategies that could improve transition cow health.

Our recent study (Basiricò et al., 2015) showed that CLA isomers have an antioxidant role by developing a significantly high redox status in bovine mammary cells. Only a few and contradictory reports have been published regarding the protective potential of aLnA, LnA, and gLnA (Arab et al., 2006b). Fagali and Catalá (2008) demonstrated in an in vitro study that CLA exhibited greater free radical quenching activity than LnA or aLnA. Therefore, the aim of the current study was to compare the effects of CLA with other EFA on the thiol redox status of cells and their protective activity against oxidative damage on mammary gland by an in vitro model based on bovine mammary epithelial cells (BME-UV1).

\section{MATERIALS AND METHODS}

\section{BME-UV1 Culture Conditions}

The BME-UV1 cell line was created at the University of Vermont from primary bovine mammary epithelial cells in culture by stable transfection with SV40 large T-antigen; BME-UV1 cells were provided by Antonella Baldi (Department FENS, University of Milan, Italy). Cells were routinely cultivated into $75-\mathrm{cm}^{2}$ tissue culture flasks (Costar, Corning, NY), in a mixture of $50 \%$ DMEM-F12, 30\% RPMI-1640, and 20\% NCTC-135 
(Sigma-Aldrich, St. Louis, MO), supplemented with $10 \%$ fetal bovine serum, $0.1 \%$ lactose, $0.1 \%$ lactalbumin hydrolysate, $1.2 \mathrm{~m} M$ glutathione, $1 \mu \mathrm{g} / \mathrm{mL}$ of insulin, $5 \mu \mathrm{g} / \mathrm{mL}$ of transferrin, $1 \mu \mathrm{g} / \mathrm{mL}$ of hydrocortisone, $0.5 \mu \mathrm{g} / \mathrm{mL}$ of progesterone, $10 \mu \mathrm{g} / \mathrm{mL}$ of L-ascorbic acid, and antibiotics (penicillin $100 \mathrm{IU} / \mathrm{mL}$; streptomycin $100 \mu \mathrm{g} / \mathrm{mL}$ ). All medium supplements were from Sigma-Aldrich. The cells were maintained at $37^{\circ} \mathrm{C}$ in a humidified $5 \% \mathrm{CO}_{2}$ incubator. Cells used in the present work were at passage number between 39 and 41 .

\section{Experimental Design}

To examine the role of fatty acids (FA) on metabolic and oxidative status of bovine mammary gland, BME-UV1 cells were resuspended in complete culture medium and, after $24 \mathrm{~h}$ of incubation, medium was removed and cells were treated for $48 \mathrm{~h}$ with complete medium containing $50 \mu \mathrm{M}$ cis-9, trans-11 CLA, trans10,cis-12 CLA, aLnA (18:3n-3), gLnA (18:3n-6), and LnA (18:2n-6). Control cells were not treated. Essential fatty acids were first dissolved in ethanol $95 \%$, and the dilutions of the stock solution were made into aqueous buffers (culture medium) before performing biological experiments. To ensure that the residual amount of organic solvent was insignificant, as organic solvents may have physiological effects at low concentrations, a control test of cell viability was performed and no cytotoxic effects or biological differences were observed (data not shown).

To test the potential protection of FA against $\mathrm{H}_{2} \mathrm{O}_{2}-$ induced oxidative stress, cells were treated as described followed by incubation at $37^{\circ} \mathrm{C}$ for $3 \mathrm{~h}$ with $\mathrm{H}_{2} \mathrm{O}_{2}(50$ $\mu M)$; the content of reactive oxygen species (ROS) and malondialdehyde (MDA) concentration were also determined. Cell viability after $48 \mathrm{~h}$ from addition of FA was determined. Reactive oxygen species and MDA were also determined in cells after $48 \mathrm{~h}$ exposure to single FA. The fatty acids tested were purchased from Larodan (Malmo, Sweden). The experiments included at least 3 replicates per treatment and were repeated at least twice.

\section{Cellular Antioxidant Response and Cell Protection}

Cell Viability Assay. Cell viability after $48 \mathrm{~h}$ of incubation with FA was determined using XTT assay with Cell Proliferation kit II [XTT: sodium 30-[1-(phenylaminocarbonyl)-3,4-tetrazolium]-bis (4-methoxy-6-nitro) benzene sulfonic acid hydrate; Roche Applied Science, Indianapolis, IL] according to the manufacturer's instructions. Briefly, cells were seeded into 96-well microplates at an optimal density (5 $\times 10^{5}$ cells $/ \mathrm{mL}$ ) and were incubated in the same condi- tions described above. For each treatment, after $48 \mathrm{~h}$ of exposure, $50 \mu \mathrm{L}$ of XTT labeling mixture was added to each well. After $24 \mathrm{~h}$ of incubation at $37^{\circ} \mathrm{C}$, absorbance was measured at $450 \mathrm{~nm}$.

Thiol Redox Status. The reduced (GSH) and the oxidized form of glutathione (GSSG) and the reduced form of NADPH contents as well as the activity of $\gamma$-glutamate cysteine ligase $(\gamma \mathbf{G C L})$ were determined for assessing the thiol redox status of BME-UV1 cells. For the determination of GSH, GSSG, and NADPH, adherent cells were detached using trypsin/EDTA solution and centrifuged at $4,500 \times g$ for $5 \mathrm{~min}$ at $4^{\circ} \mathrm{C}$. The pellet was resuspended in $200 \mu \mathrm{L}$ of PBS and lysed by 2 cycles of sonication lasted ( $100 \mathrm{~W}$ for $30 \mathrm{~s}$ ), centrifuged $\left(15,000 \times g\right.$ for $5 \mathrm{~min}$ at $\left.4^{\circ} \mathrm{C}\right)$, and stored at $-80^{\circ} \mathrm{C}$ until analysis. In cell extracts, the GSH-to-GSSG ratio and NADPH concentration were determined by colorimetric assays (BioAssay Systems, Hayward, CA). Optical density was measured by a spectrophotometer at 405 and $540 \mathrm{~nm}$ for GSH/GSSG and NADPH, respectively.

The $\gamma$ GCL activity was determined by a fluorescence assay, as described by Chen et al. (2010). The BMEUV1 cells were detached using trypsin/EDTA solution and centrifuged at $4,500 \times g$ for $5 \mathrm{~min}$ at $4^{\circ} \mathrm{C}$. The pellet was resuspended in $100 \mu \mathrm{L}$ of TES/SB buffer (wt/vol, 1/4) consisting of $20 \mathrm{~m} M$ Tris, $1 \mathrm{~m} M$ EDTA, $250 \mathrm{~m} M$ sucrose, $20 \mathrm{mM}$ sodium borate, and $2 \mathrm{mM}$ serine. The cells were sonicated at $100 \mathrm{~W}$ for $60 \mathrm{~s}$ and then centrifuged at $10,000 \times g$ at $4^{\circ} \mathrm{C}$ for $10 \mathrm{~min}$. The supernatants were collected and centrifuged again at $15,000 \times g$ at $4^{\circ} \mathrm{C}$ for $20 \mathrm{~min}$. The supernatants were collected and the protein concentrations were determined using a BCA Protein Assay Kit from Pierce (Rockford, IL), with BSA used as the standard. For the $\gamma \mathrm{GCL}$ activity assay, aliquots of $30 \mu \mathrm{L}$ of supernatant were mixed with $30 \mu \mathrm{L}$ of $\gamma \mathrm{GCL}$ reaction cocktail (400 $\mathrm{m} M$ Tris, $40 \mathrm{~m} M$ ATP, $40 \mathrm{~m} M$ L-glutamic acid, $2 \mathrm{~m} M$ EDTA, $20 \mathrm{~m} M$ sodium borate, $2 \mathrm{~m} M$ serine, and 40 $\mathrm{mM} \mathrm{MgCl}{ }_{2}$ ). Following incubation at $37^{\circ} \mathrm{C}$ for $5 \mathrm{~min}, 30$ $\mu \mathrm{L}$ of cysteine solution $(30 \mathrm{~m} M$; dissolved in TES/SB buffer) was added and the mixtures were incubated at $37^{\circ} \mathrm{C}$ for $13 \mathrm{~min}$. The enzymatic reaction in the mixture was stopped by precipitating proteins with $200 \mathrm{mM}$ 5 -sulfosalicylic acid. After placing on ice for $20 \mathrm{~min}$, the mixtures were centrifuged at $2,000 \times g$ at $4^{\circ} \mathrm{C}$ for 10 min. Following centrifugation, $20 \mu \mathrm{L}$ of each supernatant containing $\gamma$-glutamylcysteine $(\gamma \mathbf{G C})$ was added to a 96-well plate designed for fluorescence detection. For each assay, $20 \mu \mathrm{L}$ of $\gamma \mathrm{GC}$ standards, containing 5 $\mu \mathrm{L}$ of $\gamma \mathrm{GC}$ reaction cocktail [5 $\mu \mathrm{L}$ of 5 -sulfosalicylic acid $(200 \mathrm{mM}), 5 \mu \mathrm{L}$ of $\mathrm{H}_{2} \mathrm{O}$, and $5 \mu \mathrm{L}$ of $\gamma \mathrm{GC}$ standard solution $(0,20,40,60,80,100,120$, and $140 \mu M$ in TES/SB buffer)] was added to each well of the same 96-well plate to generate a standard curve. Next, 180 
$\mu \mathrm{L}$ of 2,3-naphthalenedicarboxyaldehyde was added to each well. Following incubation in the dark at room temperature for $30 \mathrm{~min}$, the formation of 2,3-naphthalenedicarboxyaldehyde- $\gamma \mathrm{GC}$ was measured (472 $\mathrm{nm}$ excitation/528 $\mathrm{nm}$ emission) using a fluorescent plate reader (Multimode Detector DTX 880, Beckman Coulter Inc., Fullerton, CA). The production of $\gamma \mathrm{GC}$ in each sample was calculated using the standard curve. Values were expressed in micromoles per minute per microgram of total proteins.

Measurement of MDA Production. For the determination of MDA, adherent cells were detached using trypsin/EDTA solution and centrifuged at 4,500 $\times g$ for $5 \mathrm{~min}$ at $4^{\circ} \mathrm{C}$. The pellet was resuspended in $200 \mu \mathrm{L}$ of PBS and lysed by 2 cycles of sonication at $100 \mathrm{~W}$ for $30 \mathrm{~s}$, centrifuged at $15,000 \times g$ for $5 \mathrm{~min}$ at $4^{\circ} \mathrm{C}$, and stored at $-80^{\circ} \mathrm{C}$ until analysis. In cell extracts MDA concentrations were determined by colorimetric assays (Abcam, Cambridge, UK). Optical density was measured by a spectrophotometer at $540 \mathrm{~nm}$.

Measurement of ROS Production. To determine ROS concentration, cells were washed twice with PBS and incubated with $20 \mu M 2^{\prime}, 7^{\prime}$-dichlorodihydrofluorescin diacetate probe (DCFH-DA) in PBS at $37^{\circ} \mathrm{C}$ for $40 \mathrm{~min}$. Fluorescence was measured at 485 (excitation) and $535 \mathrm{~nm}$ (emission) wavelengths on a microplate reader (Multimode Detector DTX 880, Beckman Coulter Inc.).

\section{Statistical Analysis}

All data of the experiment are presented as least squares means and standard error of the means. The data were analyzed by ANOVA using Statistica-7 software package (StatSoft Inc., Tulsa, OK). The significance of the differences was assessed by the Fisher's least square difference (LSD) test. Significance was declared at $P<0.05$.

\section{RESULTS}

\section{Effect of FA on Cell Viability in BME-UV1}

Cell viability was carried out using the XTT assay and was evaluated after $48 \mathrm{~h}$ of FA exposure. As shown in Figure 1, no FA treatment reduced cell viability, and no differences were observed between treatments. This assay indicated that the exposure to different FA did not show any cytotoxic effect.

\section{Effect of FA on Thiol Redox Status in BME-UV1}

Oxidized and Reduced Glutathione. The levels of nonenzymatic antioxidants, such as GSH, are depicted in Figure 2. Compared with the control, an increase $(P$ $<0.01$ ) of reduced GSH was showed in cells treated with cis-9,trans-11 CLA, aLnA, gLnA, LnA, and with

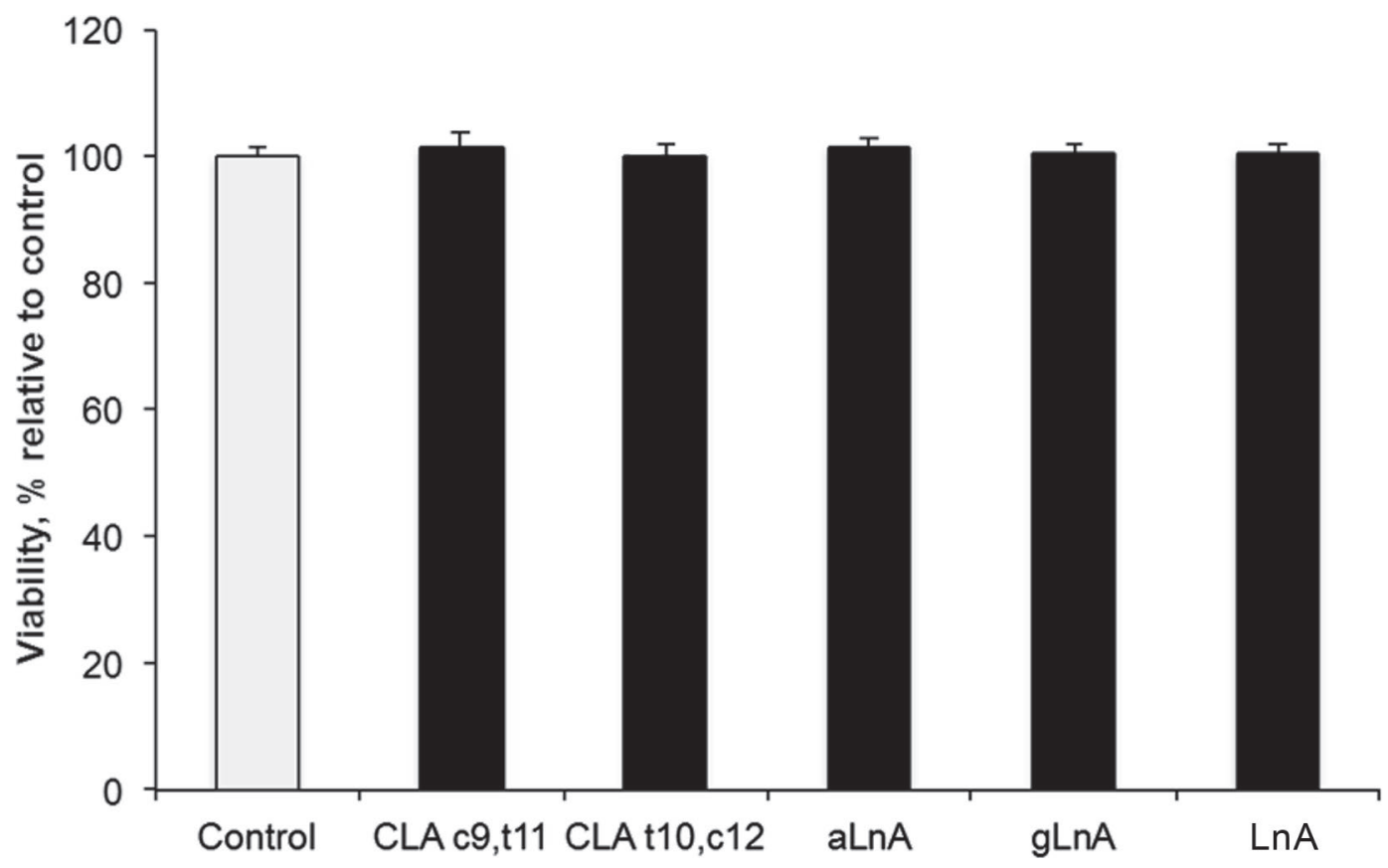

Figure 1. Cell viability of bovine mammary epithelia cells (BME-UV1) cells evaluated after $48 \mathrm{~h}$ of exposure to fatty acids. Data are reported as $\operatorname{LSM} \pm \operatorname{SEM}(\mathrm{n}=6) . \mathrm{c}=$ cis; $\mathrm{t}=$ trans; $\mathrm{aLnA}=\alpha$-linolenic acid; gLnA $=\gamma$-linolenic acid; $\operatorname{LnA}=$ linoleic acid. 
trans-10,cis-12 CLA $(P<0.05 ;$ Figure 2A). Among treatments, values of reduced GSH were significantly higher $(P<0.01)$ in cells treated with aLnA and LnA compared with cis-9,trans-11 CLA, gLnA, and trans10,cis-12 CLA. Reduced GSH levels in cells treated with cis-9,trans-11 CLA and gLnA were not different, but differed significantly $(P<0.01)$ from those treated with trans-10,cis-12 CLA. No differences in the level of oxidized GSH were noted for cells treated with FA compared with the control culture (Figure 2B). The ratio of GSH to GSSG showed the same trend of reduced GSH (Figure 2C).

Quantitative Determination of NADPH. Concentrations of a redox coenzyme NADPH are reported in Figure 3. Compared with the control, a greater level of NADPH was observed in cells treated with cis9,trans-11 CLA, aLnA, gLnA, LnA $(P<0.01)$, and trans-10,cis-12 CLA $(P<0.05)$. The cis-9,trans-11 CLA showed greater $(P<0.01)$ concentration of NADPH than all other FA; the values of NADPH were not significantly different between aLnA, gLnA, and LnA, whereas NADPH in the trans-10, cis-12 CLAtreated cells was significantly lower $(P<0.05)$ than cells treated with aLnA and LnA.

$\gamma-G C$ Ligase Activity. Thiol redox status was also assessed by measuring $\gamma$ GCL activity (Figure 4 ). After the $48 \mathrm{~h}$, all $\mathrm{FA}$ induced a strong antioxidant response by increasing $(P<0.01)$ the intracellular $\gamma$ GCL activity compared with the control. Among treatments, higher $\gamma$ GCL activity $(P<0.01)$ was observed in gLnA treatment compared with other FA. The enzyme activity was not different between cis-9,trans-11 CLA, aLnA, and LnA treatments, and was lower $(P<0.01)$ in cells treated with trans-10,cis-12 CLA compared with other FA.

Intracellular ROS and MDA. Intracellular ROS production by dichlorofluorescein (DCFH-DA) fluorescence measurement was assessed in cells supplemented with FA (Figure 5A). Cells treated with FA showed an increase $(P<0.01)$ of ROS production compared with the control. Cells treated with gLnA showed the greatest levels $(P<0.01)$ of ROS compared with the other FA. Both CLA isomers showed the same and lower levels $(P<0.01)$ of ROS production compared with other FA treatments.

Cell concentrations of MDA are shown in Figure 5B. All FA reduced $(P<0.01)$ the MDA level compared with untreated cells. Among treatments, cells treated with trans-10,cis-12 CLA and LnA showed similar MDA levels and much more lower $(P$-value ranged from $<0.05$ to $<0.01)$ than the other FA. Malondialdehyde in cells treated with aLnA was not different than trans10,cis-12 CLA, but was greater $(P<0.01)$ compared with LnA. The MDA values of cis-9,trans-11 CLA was greater $(P<0.01)$ than trans-10, cis-12 CLA, aLnA, and LnA. Cells treated with gLnA showed greater $(P<$ 0.01) levels of MDA compared with other FA.
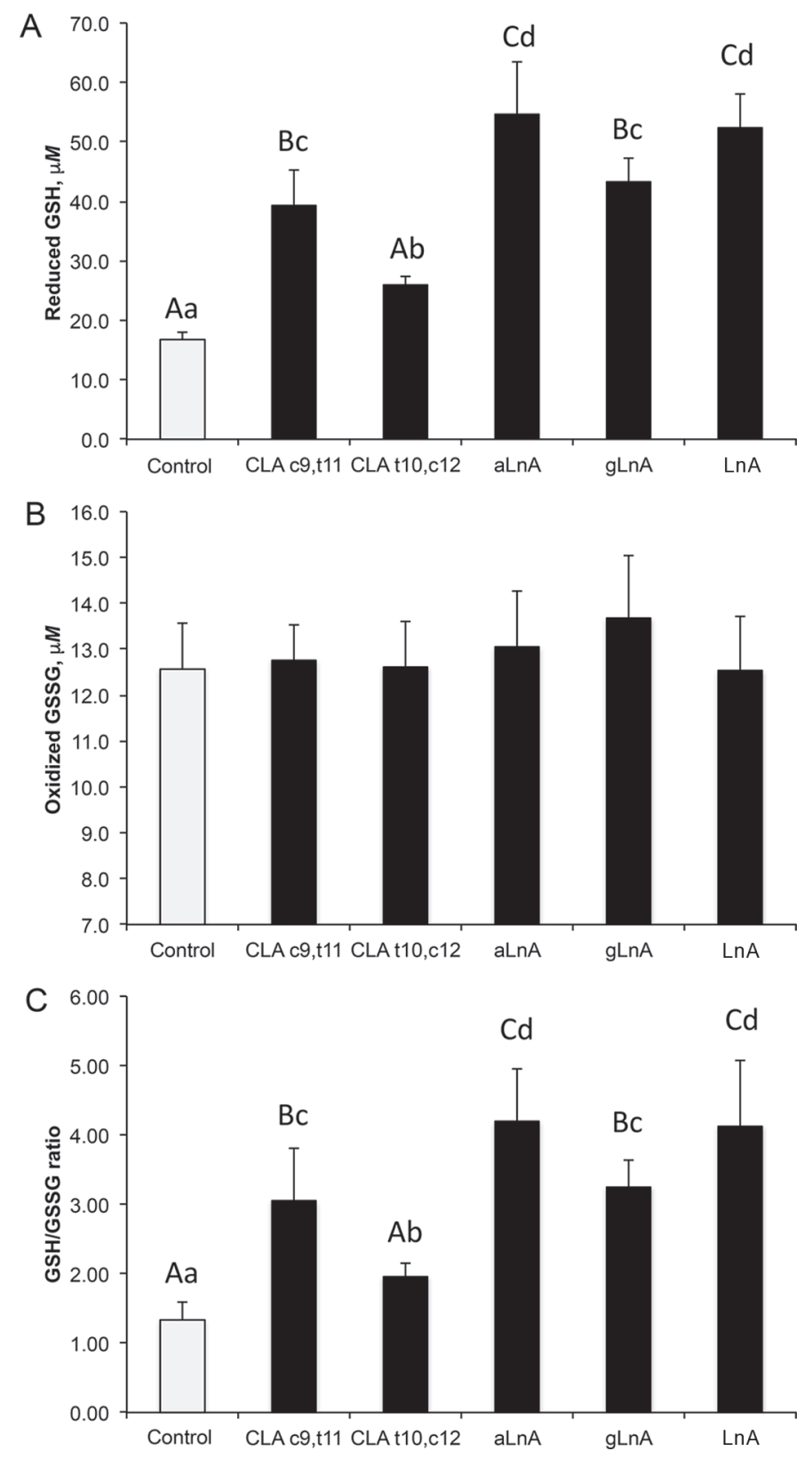

Figure 2. Intracellular concentration of reduced glutathione (GSH; A), oxidized glutathione (GSSG; B), and GSH-to-GSSG ratio (C) in bovine mammary epithelia cells (BME-UV1) after $48 \mathrm{~h}$ of exposure to fatty acids. Data are reported as least squares means \pm SEM $(n=6)$. Significant differences among control and treatments are represented by different letters $(\mathrm{a}-\mathrm{d}=P<0.05 ; \mathrm{A}-\mathrm{C}=P<0.01) . \mathrm{c}=$ cis; $\mathrm{t}$ $=$ trans; $\operatorname{aLn} \mathrm{A}=\alpha$-linolenic acid; gLnA $=\gamma$-linolenic acid; $\operatorname{Ln} \mathrm{A}=$ linoleic acid. 


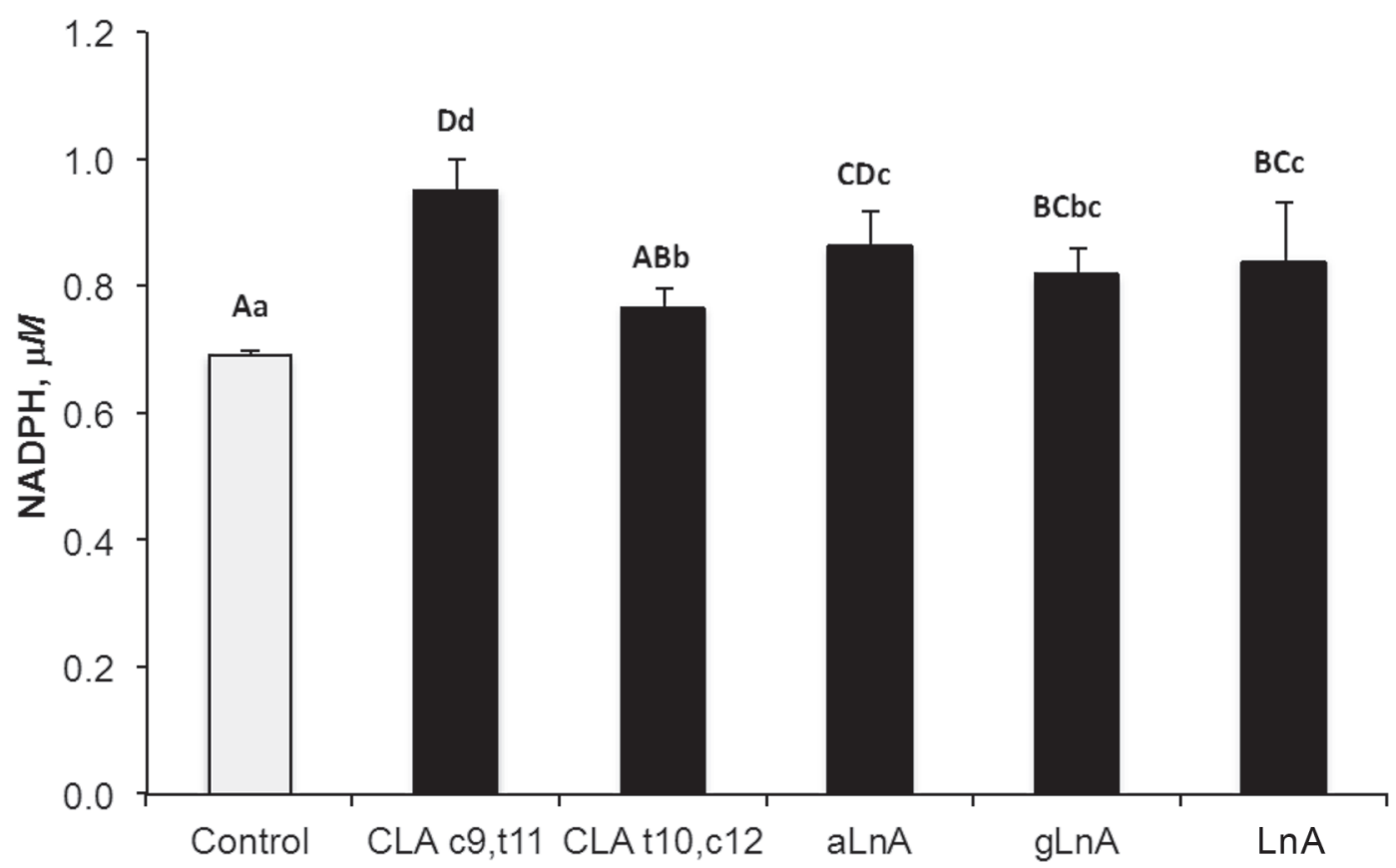

Figure 3. Intracellular concentration of NADPH after $48 \mathrm{~h}$ of exposure to fatty acids. Data are reported as least squares means \pm SEM (n $=6$ ). Significant differences among control and treatments are represented by different letters $(\mathrm{a}-\mathrm{d}=P<0.05 ; \mathrm{A}-\mathrm{D}=P<0.01) . \mathrm{c}=$ cis; $\mathrm{t}=$ trans; aLnA $=\alpha$-linolenic acid; gLnA $=\gamma$-linolenic acid; $\operatorname{Ln} \mathrm{A}=$ linoleic acid.

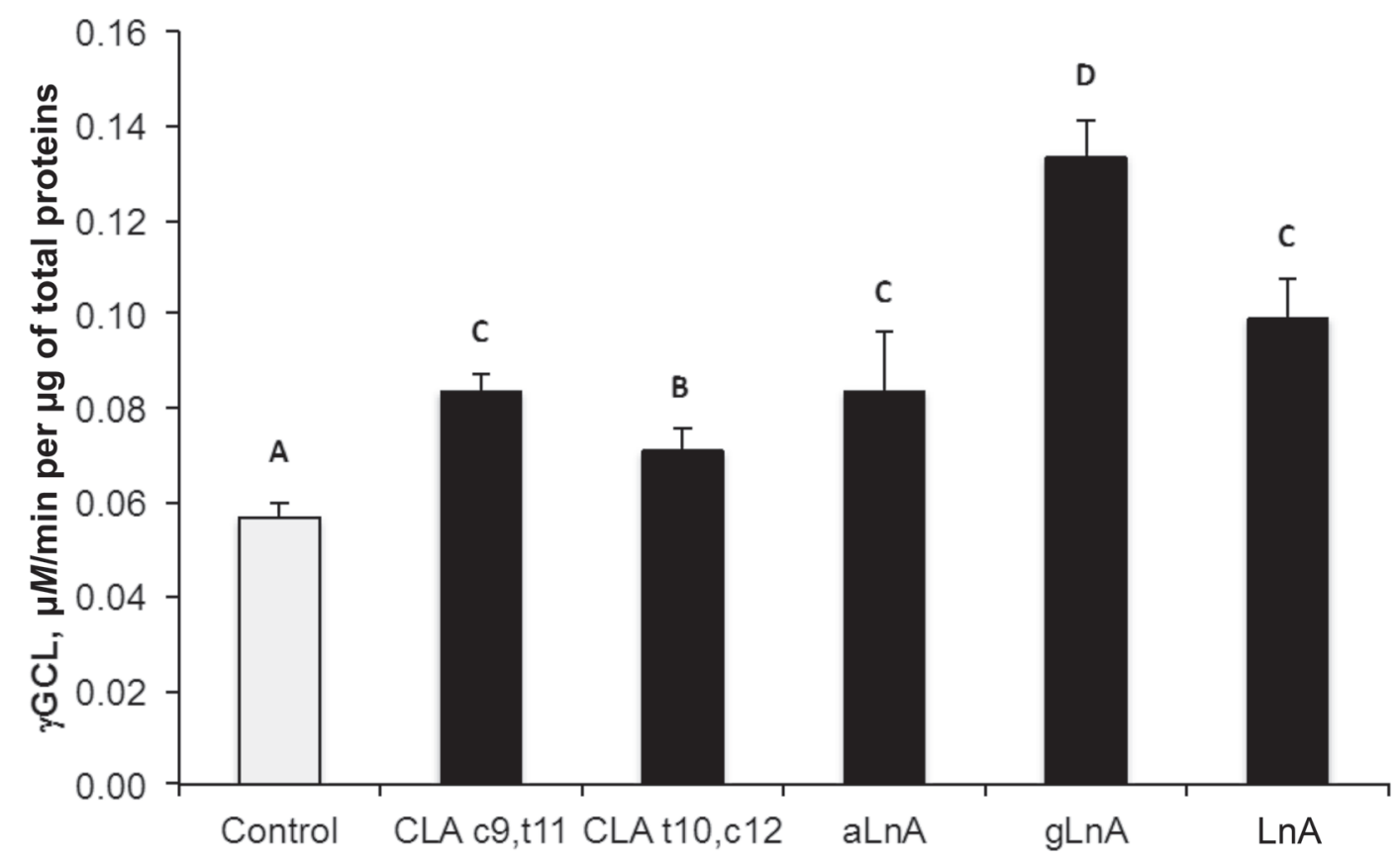

Figure 4. Intracellular activity of $\gamma$-glutamate cysteine ligase $(\gamma \mathrm{GCL})$ after $48 \mathrm{~h}$ of exposure to fatty acids. Data are reported as least squares means \pm SEM $(\mathrm{n}=6)$. Significant differences among control and treatments are represented by different letters $(\mathrm{A}-\mathrm{D}=P<0.01) . \mathrm{c}=$ cis; $\mathrm{t}$ $=$ trans; aLnA $=\alpha$-linolenic acid; gLnA $=\gamma$-linolenic acid; LnA $=$ linoleic acid. 

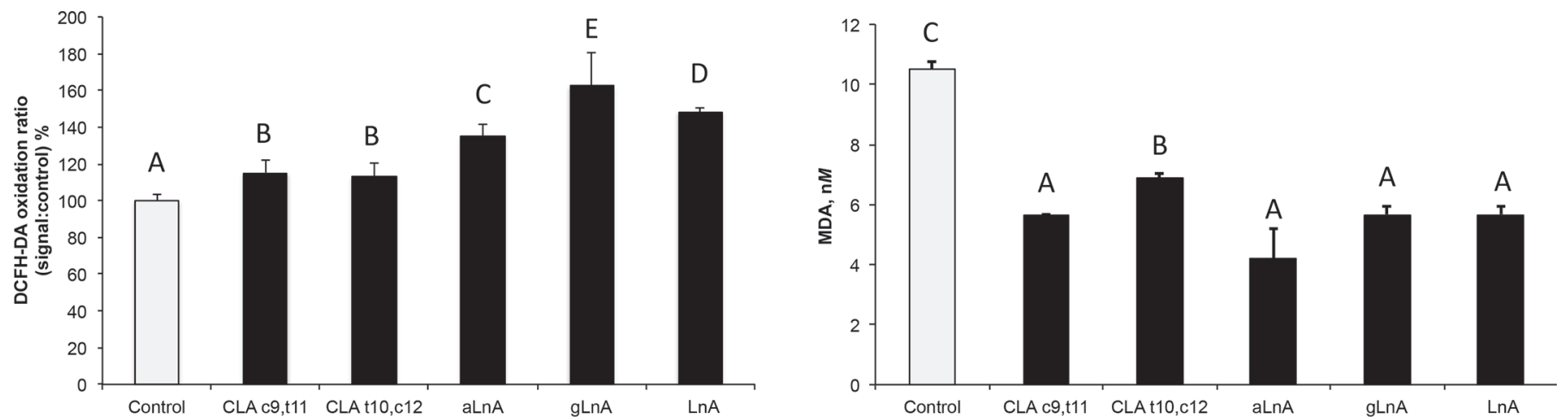

Figure 5. Intracellular production of reacting oxygen species by dichloro-dihydro-fluorescein diacetate assay (DCFH-DA) and malondialdehyde (MDA; B) in bovine mammary epithelia cells (BME-UV1) cells after $48 \mathrm{~h}$ of exposure to fatty acids. Data are reported as least squares means \pm SEM $(\mathrm{n}=6)$. Significant differences among control and treatments are represented by different letters $(\mathrm{A}-\mathrm{E}=P<0.01) . \mathrm{c}=$ cis; $\mathrm{t}$ $=$ trans; $\mathrm{aLnA}=\alpha$-linolenic acid; $\mathrm{gLnA}=\gamma$-linolenic acid; $\operatorname{Ln} \mathrm{A}=$ linoleic acid.

\section{Effect of FA on Protection of Cells Against Oxidative Stress}

To evaluate and to compare the potential protection of different FA against $\mathrm{H}_{2} \mathrm{O}_{2}$-induced oxidative stress, ROS test after $3 \mathrm{~h}$ to $\mathrm{H}_{2} \mathrm{O}_{2}$ exposure was assessed. As shown in Figure 6, all FA were not able to enhance cell resistance against oxidative stress at $48 \mathrm{~h}$. The CLA-treated cells showed a ROS production similar to the control and significantly lower $(P<0.01)$ than the other FA. The ROS production was greater $(P<0.01)$ in cells treated with, aLnA, gLnA, and LnA compared with the control. Cells treated with gLnA showed a greater $(P<0.01)$ concentration of ROS compared with the other FA. All FA showed lower $(P<0.01)$ MDA levels compared with control cells (Figure 7). Among FA, aLnA and gLnA showed higher $(P<0.05)$ MDA levels compared with their counterparts.

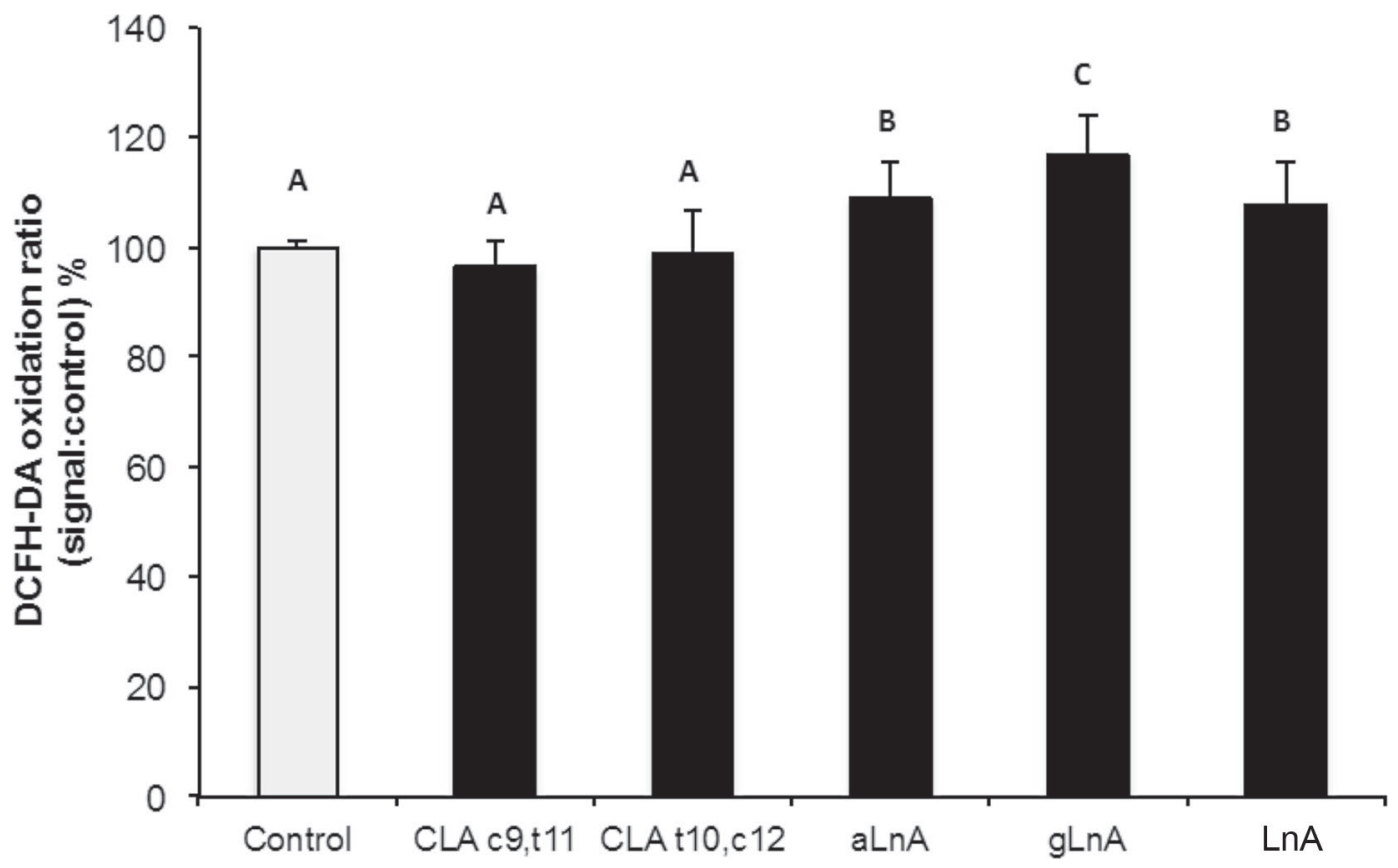

Figure 6. Intracellular production of reacting oxygen species by dichloro-dihydro-fluorescein diacetate assay (DCFH-DA). After $48 \mathrm{~h}$ of exposure to fatty acids, cells were treated for $3 \mathrm{~h}$ with $\mathrm{H}_{2} \mathrm{O}_{2}(50 \mu M)$. Data are reported as least squares means \pm SEM (n $=6$ ). Significant differences among control and treatments are represented by different letters $(\mathrm{A}-\mathrm{C}=P<0.01)$. $\mathrm{c}=$ cis; $\mathrm{t}=$ trans; aLnA $=\alpha$-linolenic acid; $\mathrm{gLnA}=\gamma$-linolenic acid; $\operatorname{LnA}=$ linoleic acid. 


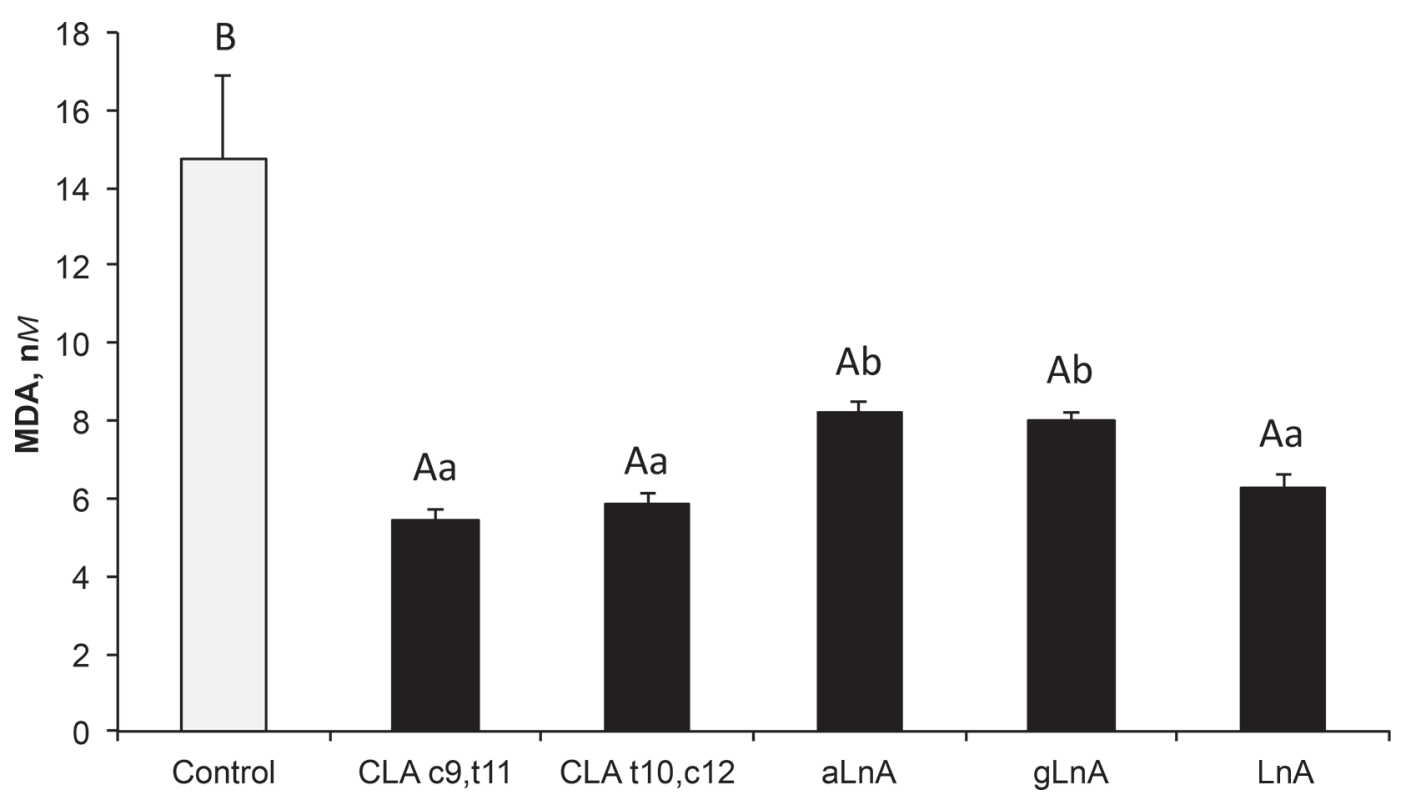

Figure 7. Intracellular production of malondialdehyde (MDA). After $48 \mathrm{~h}$ of exposure to fatty acids, cells were treated for $3 \mathrm{~h}$ with $\mathrm{H}_{2} \mathrm{O}_{2}$ $(50 \mu M)$. Data are reported as least squares means \pm SEM $(\mathrm{n}=6)$. Significant differences among control and treatments are represented by different letters $(\mathrm{a}, \mathrm{b}=P<0.05 ; \mathrm{A}, \mathrm{B}=P<0.01) . \mathrm{c}=$ cis; $\mathrm{t}=$ trans; $\mathrm{aLnA}=\alpha$-linolenic acid; $\mathrm{gLnA}=\gamma$-linolenic acid; LnA $=$ linoleic acid.

\section{DISCUSSION}

In the present report we investigated the effect of several FA (cis-9,trans-11 CLA, trans-10,cis-12 CLA, aLnA, gLnA, and LnA) on the cellular antioxidant response and on lipoperoxidation in BME-UV1 cells. Our results have shown that the bovine cell line BME-UV1 has different susceptibilities to treatment with different EFA and CLA.

In our experimental conditions, the exposure to 50 $\mu M \mathrm{FA}$ for $48 \mathrm{~h}$ strengthened the cellular defenses against to oxidative damage compared with control cells. We observed that the cell supplementation of FA induced higher levels of reduced GSH, matched by high activity of $\gamma \mathrm{GCL}$ and an increase of NADPH concentration; in particular, GSH synthesis was upregulated by different PUFA, mainly through an induction of $\gamma$ GCL. The data presented here are consistent with our previous study (Basiricò et al., 2015) and with other findings indicating an improved antioxidant status in cells treated with CLA and EFA (Arab et al., 2006b; Espinosa-Diez et al., 2015).

Reduced glutathione plays a primary role in the maintenance of intracellular redox homeostasis by affording protection against reactive oxygen and nitrose species as well as electrophilic xenobiotics. Under normal cellular redox conditions, the major portion of this redox regulator is in the form of GSH, whereas GSSG concentration increases during oxidative stress. Reduced glutathione is synthesized from its constituent
AA, forming a tripeptide thiol; this synthesis requires 2 ATP-dependent steps. The first and limiting synthesis is catalyzed by $\gamma \mathrm{GCL}$ and the second step is mediated by GSH synthetase. Above all, an induction of $\gamma \mathrm{GCL}$ is characteristic of an antioxidant response (Lee et al., 2003; Rahman, 2005). Moreover, NADPH is essential in GSH recycling and related antioxidant functions, and the ratio of the reduced to total pyridine nucleotide pool is generally accepted as an indicator of the cellular redox status (Adams et al., 2001).

In vivo study on rats fed oils with high levels of aLnA improved the antioxidant status of hepatic tissue with the increase of GSH content and the GSH-to-GSSG ratio without modification of the levels of GSSG (RincónCervera et al., 2016). Ramos and Colquhoun (2003) observed that gLnA and EPA in rat C6 glioma cell increased NADPH production, permitting the maintenance of adequate intracellular reduced glutathione concentrations and limiting rates of lipid peroxidation and ROS generation. Bergamo et al. (2011) reported that isomeric mixture of CLA (cis-9,trans-11 and trans10,cis-12) administration in MGFD mice resulted in a significant enhancement of GSH content and upregulated the expression of the $\gamma \mathrm{GCL}$ mRNA and protein. The upregulation of $\gamma \mathrm{GCL}$ and glutathione reductase was observed in human fibroblast cells treated for 24 and $48 \mathrm{~h}$ with docosahexaenoic acid (n-3 PUFA; Arab et al., 2006a). Mollica et al. (2014) showed that cis9,trans-11 CLA supplementation to rats improves the GSH-to-GSSG ratio in the liver, and nuclear factor 
erythroid 2-related factor 2 (Nrf2) activity. Cui et al. (2016), in primary mouse hepatocytes treated with different FA (saturated and unsaturated, including LnA, aLnA, and AA) for $24 \mathrm{~h}$, observed an enhancement of Nrf2 transcription factor at the mRNA and protein levels. Bergamo et al. (2008), in murine dendritic cells, demonstrated the ability of cis-9,trans-11 CLA to activate cytoprotective mechanisms induced via Nrf2/ARE (antioxidant response element).

These results provide a basis for the hypothesis that, in our experiments, the capacity of FA to positively stimulate the availability of antioxidant enzyme could be related to the ability in activating the Nrf2 transcription factor. The Nrf2 pathway is the major regulator of cytoprotective responses to oxidative and electrophilic stress (Abuelo et al., 2015; Espinosa-Diez et al., 2015). Under basal conditions, Nrf2 is sequestered in the cytosol by a Keap1 homodimer, which facilitates the ubiquitination and proteasomal degradation of Nrf2. Inducers react with specific cysteine residues in Keap1, leading to the release of Nrf2, owing its nuclear translocation. In the nucleus, Nrf2 heterodimerizes together with small Maf proteins and binds to the antioxidant response element, activating the expression of a battery of cytoprotective genes, such as NAD(P)H:quinone oxidoreductase (NQO1), glutathione S-transferases, and $\gamma$ GCL (Lee et al., 2003).

On BME-UV1 cells, in addition to the evaluation of antioxidants, ROS amount and MDA concentration were measured. Although the amount of free radicals was higher in all cells treated with FA compared with the control, the cells treated with cis-9,trans-11 CLA and trans-10,cis-12 CLA showed lower levels of ROS production than the other FA. Espinosa-Diez et al. (2015) reported that low or moderate concentrations of ROS, historically considered as cellular damaging agents, are also involved in physiological responses as part of signaling processes, such as activation or deactivation cycles of redox metabolism and expression of antioxidant enzymes expression that are essential to maintain oxidant-antioxidant balance in the cells. In fact, ROS protects the cell against ROS damage by inducing different antioxidant responses and re-establishing or maintaining redox homeostasis. Moreover, ROS can activate Nrf2 (Nair et al., 2008), which in turn counteracts proinflammatory signaling pathways (Kim et al., 2010). These results support the hypothesis that the treatment of BME-UV1 with FA might initiate cellular antioxidant responses through Nrf2-mediated activation of antioxidant and detoxifying enzymes.

Malondialdehyde concentration has been employed for some time as a biomarker for lipid peroxidation of n-3 and n-6 FA (Ayala et al., 2014). Lipid peroxidation can be described generally as a process under which ox- idants, such as free radicals, take electrons from lipids. Lipid peroxidation is a chain reaction initiated by the hydrogen abstraction or addition of an oxygen radical, resulting in the oxidative damage of PUFA (Repetto et al., 2012). In our study, all FA supplementation decreased the cellular concentration of MDA compared with the control. This would demonstrate a protective effect of FA against the lipoperoxidation. In fact, the lowest presence of end-products such as MDA can be translated into a lower concentration of peroxyl radical and hydroperoxyl, both triggering factors of lipid oxidation. The reduced concentration of oxidizing agents may be linked to the enhanced GSH content and rely on $\gamma \mathrm{GCL}$ and NADPH induction.

Finally, the measurement of ROS and MDA production in the presence of $\mathrm{H}_{2} \mathrm{O}_{2}$ were used as further tests to check and compare the potential protection of different $\mathrm{FA}$ against $\mathrm{H}_{2} \mathrm{O}_{2}$-induced oxidative stress. The protective effects of the $5 \mathrm{FA}$ studied were not identical in mammary cells, and FA induced different ROS and MDA levels in bovine mammary epithelial cells. Hydrogen peroxide challenge of cells, which were preincubated with LnA, aLnAn or gLnAn produced oxidative damage beyond the control group whereas the same challenge of the cells with CLA isomers did not differ from the control cells in terms of oxidative stress. This might also be explained by extracellular formed lipid(per)oxidation products.

All FA strongly reduced the lipoperoxidation in cells after $\mathrm{H}_{2} \mathrm{O}_{2}$ exposure. Both CLA and LA seem to have a better protective effect compared with aLnA and gLnA. The antioxidative effect of CLA against lipoperoxidation has been recently demonstrated in lactating dairy cows (Hanschke et al., 2016).

This is an interesting finding, considering the fact that in the course of evolution cows developed the ability to alter EFA through biohydrogenation, leading to the synthesis of CLA, which may play a more significant role than the EFA ingested from dietary sources. Conjugated linoleic acid protection seems to be mediated not only to the levels of GSH, as reduced GSH and GSH-to-GSSG ratio and the activity of $\gamma$ GCL enzyme were lower compared with other FA. In addition, Arab et al. (2006b) reported that, among the 8 FA tested, CLA was the only PUFA able to have a protective action against oxidative insult in human skin fibroblasts. Richard et al. (2008) reported that supplementation of human aortic endothelial cells with PUFA of the n-3 series resulted in lower formation of ROS as compared with cells supplemented with SFA, MUFA, or PUFA of the n- 6 series. Furthermore, because of varying protective mechanisms by different FA on intracellular oxidative stress and cell response, the expressions of ROS production, with or without $\mathrm{H}_{2} \mathrm{O}_{2}$, did not show the 
same variation tendency for all FA. Interestingly, the results indicated that, in BME-UV1 cells, gLnA was more potent in inducing ROS production and MDA than other UFA. A possible explanation could be that gLnA, being a precursor of ArA, can be quickly used as inflammatory mediator.

The capability to mitigate the negative effects of $\mathrm{H}_{2} \mathrm{O}_{2}$ by CLA isomers better compared with other FA can be explained, in part, by the fact that lactating cows have the ability to endogenously synthesize CLA. In particular, the mammary gland plays a role of primary importance in the endogenous synthesis of cis-9,trans-11 CLA. Differences in cellular uptake, incorporation, and metabolization of CLA compared with EFA probably play a significant role in the effect of these different compounds on cell response. Given the results of this and of other studies, we conclude that CLA isomers are more effective on cellular level than EFA because they are natural and more familiar to ruminant cells.

\section{CONCLUSIONS}

We investigated the effect of several FA on the cellular antioxidant response and on lipoperoxidation in BME-UV1 cells. Results indicate that all FA were able to upregulate the $\gamma$-GCL activity and enhance GSH synthesis and reduce lipoperoxidation. It is worth noting that CLA isomers supplementation, compared with other EFA, does not contribute to further increase of $\mathrm{H}_{2} \mathrm{O}_{2}$-induced ROS production. The increase of GSH synthesis observed in cells treated with all FA is not sufficient to control $\mathrm{H}_{2} \mathrm{O}_{2}$ production induced by $\mathrm{H}_{2} \mathrm{O}_{2}$. In this study, the increased availability of GSH was probably used by other pathways, including reactions of transferases with xenobiotics or with lipid peroxidation products. As ruminants have a natural supply of CLA, further research should consider whether this feature is an evolutionary advantage for the cow.

\section{ACKNOWLEDGMENTS}

The study was financially supported by BASF SE, Ludwigshafen, Germany.

\section{REFERENCES}

Abuelo, A., J. Hernandez, J. L. Benedito, and C. Castillo. 2015. The importance of the oxidative status of dairy cattle in the periparturient period: revisiting antioxidant supplementation. J. Anim. Physiol. Anim. Nutr. (Berl.) 99:1003-1016.

Adams, J. D., Jr., L. K. Klaidman, M. L. Chang, and J. Yang. 2001. Brain oxidative stress - Analytical chemistry and thermodynamics of glutathione and NADPH. Curr. Top. Med. Chem. 1:473-482.

Andreoli, M. F., P. G. Illesca, M. A. González, and C. A. Bernal. 2010. Conjugated linoleic acid reduces hepatic steatosis and restores liv- er triacylglycerol secretion and the fatty acid profile during protein repletion in rats. Lipids 45:1035-1045.

Arab, K., A. Rossary, F. Flourie, Y. Tourneur, and J. P. Steghens. 2006a. Docosahexaenoic acid enhances the antioxidant response of human fibroblasts by upregulating $\gamma$-glutamyl-cysteinyl ligase and glutathione reductase. Br. J. Nutr. 95:18-26.

Arab, K., A. Rossary, L. Soulère, and J. P. Steghens. 2006b. Conjugated linoleic acid, unlike other unsaturated fatty acids, strongly induces glutathione synthesis without any lipoperoxidation. Br. J. Nutr. 96:811-819.

Ayala, A., M. F. Muñoz, and S. Argüelles. 2014. Lipid peroxidation: Production, metabolism, and signaling mechanisms of malondialdehyde and 4-hydroxy-2-nonenal. Oxid. Med. Cell. Longev. 2014:360438.

Basiricò, L., P. Morera, D. Dipasquale, A. Tröscher, A. Serra, M. Mele, and U. Bernabucci. 2015. Conjugated linoleic acid isomers strongly improve the redox status of bovine mammary epithelial cells (BME-UV1). J. Dairy Sci. 98:7071-7082.

Bauman, D. E., and A. L. Lock. 2006. Conjugated linoleic acid: Biosynthesis and nutritional significance. Pages 93-136 in Advances in Conjugated Linoleic Acid Research, Vol. 2, 3rd ed. AOCS Press, Springer, New York, NY.

Bauman, D. E., J. W. I. Perfield, K. J. Harvatine, and L. H. Baumgard. 2008. Regulation of fat synthesis by conjugated linoleic acid: lactation and the ruminant model. J. Nutr. 138:403-409.

Benjamin, S., and F. Spener. 2009. Conjugated linoleic acids as functional food: An insight into their health benefits. Nutr. Metab. (Lond.) 6:36.

Bergamo, P., M. Gogliettino, G. Palmieri, E. Cocca, F. Maurano, R. Stefanile, M. Balestrieri, G. Mazzarella, C. David, and M. Rossi. 2011. Conjugated linoleic acid protects against gliadin-induced depletion of intestinal defenses. Mol. Nutr. Food Res. 55:S248-256.

Bergamo, P., F. Maurano, R. D'Arienzo, C. David, and M. Rossi. 2008. Association between activation of phase 2 enzymes and down-regulation of dendritic cell maturation by c9,t11-conjugated linoleic acid. Immunol. Lett. 117:181-190.

Bernabucci, U., B. Ronchi, N. Lacetera, and A. Nardone. 2005. Influence of body condition score on relationships between metabolic status and oxidative stress in periparturient dairy cows. J. Dairy Sci. 88:2017-2026.

Caldari-Torres, C., A. L. Lock, C. R. Staples, and L. Badinga. 2011. Performance, metabolic, and endocrine responses of periparturient Holstein cows fed 3 sources of fat. J. Dairy Sci. 94:1500-1510.

Castillo, C., J. Hernandez, A. Bravo, M. Lopez-Alonso, V. Pereira, and J. L. Benedito. 2005. Oxidative status during late pregnancy and early lactation in dairy cows. Vet. J. 169:286-292.

Chen, C. N., H. M. Brown-Borg, S. G. Rakoczy, D. A. Ferrington, and L. V. Thomposon. 2010. Aging impairs the expression of the catalytic subunit of glutamate-cysteine ligase in soleus muscle under stress. J. Gerontol. A Biol. Sci. Med. Sci. 65:129-137.

Chinnadurai, K., H. K. Kanwal, A. K. Tyagi, C. Stanton, and P. Ross. 2013. High conjugated linoleic acid enriched ghee (clarified butter) increases the antioxidant and antiatherogenic potency in female Wistar rats. Lipids Health Dis. 12:121.

Cui, Y., W. Qiuju, T. Xing, and Z. Xiuying. 2016. Effects of fatty acids on CYP2A5 and Nrf2 expression in mouse primary hepatocytes. Biochem. Genet. 54:29-40.

Das, U. N. 2006. Biological significance of essential fatty acids. J. Assoc. Physicians India 54:309-319.

Dirandeh, E., A. Towhidi, S. Zeinoaldini, M. Ganjkhanlou, Z. Ansari Pirsaraei, and A. Fouladi Nashta. 2013. Effects of different polyunsaturated fatty acid supplementations during the postpartum periods of early lactating dairy cows on milk yield, metabolic responses, and reproductive performances. J. Anim. Sci. 91:713-721.

Du, R., T. Zhong, W. Q. Zhang, P. Song, W. D. Song, Y. Zhao, C Wang, Y. Q. Tang, X. Zhang, and Q. Zhang. 2014. Antitumor effect of iRGD-modified liposomes containing conjugated linoleic acid-paclitaxel (CLA-PTX) on B16-F10 melanoma. Int. J. Nanomedicine 9:3091-3105.

Elgersma, A., G. Ellen, H. van der Horst, H. Boer, P. R. Dekker, and S. Tamminga. 2004. Quick changes in milk fat composition from 
cows after transition from fresh grass to a silage diet. Anim. Feed Sci. Technol. 117:13-27.

Elgersma, A., S. Tamminga, and G. Ellen. 2006. Modifying milk composition through forage. Anim. Feed Sci. Technol. 131:207-225.

Espinosa-Diez, C., V. Miguel, D. Mennerich, T. Kietzmann, P. Sánchez-Pérez, S. Cadenas, and S. Lamas. 2015. Antioxidant responses and cellular adjustments to oxidative stress. Redox Biol. 6:183-197.

Fagali, N., and A. Catalá. 2008. Antioxidant activity of conjugated linoleic acid isomers, linoleic acid and its methyl ester determined by photoemission and DPPH techniques. Biophys. Chem. 137:56-62.

Galamb, E., V. Faigl, M. Keresztes, Z. Csillik, A. Tröscher, P. Elek, M. Kulcsár, G. Huszenicza, H. Fébel, and F. Husvéth. 2016. Effect of pre- and post-partum supplementation with lipid-encapsulated conjugated linoleic acid on milk yield and metabolic status in multiparous high-producing dairy cows. J. Anim. Physiol. Anim. Nutr. (Berl.) https://doi.org/10.1111/jpn.12544.

Gessner, D. K., E. Most, G. Schlegel, K. Kupczyk, F. J. Schwarz, and K. Eder. 2015. Concentrations of retinol and tocopherols in the milk of cows supplemented with conjugated linoleic acid. J. Anim. Physiol. Anim. Nutr. (Berl.) 99:1039-1046.

Hanschke, N., M. Kankofer, L. Ruda, M. Holtershinken, U. Meyer, J. Frank, S. Danicke, and J. Rehage. 2016. The effect of conjugated linoleic acid supplements on oxidative and antioxidative status of dairy cows. J. Dairy Sci. 99:8090-8102.

Hofmann, R. R., and D. R. M. Stewart. 1972. Grazer or Browser: A classification based on the stomach structure and feeding habits of East African ruminants. Marnmalia 36:226-240.

Kim, Y. R., J. E. Oh, M. S. Kim, M. R. Kang, S. W. Park, J. Y. Han, H. S. Eom, N. J. Yoo, and S. H. Lee. 2010. Oncogenic Nrf2 mutations in squamous cell carcinomas of oesophagus and skin. J. Pathol. 220:446-451.

Lee, J. M., M. J. Calkins, K. Chan, Y. W. Kan, and J. A. Johnson. 2003. Identification of the NF-E2-related factor-2-dependent genes conferring protection against oxidative stress in primary cortical astrocytes using oligonucleotide microarray analysis. J. Biol. Chem. 278:12029-12038.

Leroy, J. L. M. R., R. G. Sturmey, V. Van Hoeck, J. De Bie, P. J. McKeegan, and P. E. J. Bols. 2013. Dietary lipid supplementation on cow reproductive performance and oocyte and embryo viability: A real benefit? Anim. Reprod. 10:258-267.

Lessard, M., N. Gagnon, and H. V. Petit. 2003. Immune response of postpartum dairy cows fed flaxseed. J. Dairy Sci. 86:2647-2657.

Lunn, J., and H. E. Theobald. 2006. The health effects of dietary unsaturated fatty acids. Nutr. Bull. 31:178-224. https://doi. org/10.1111/j.1467-3010.2006.00571.x.

Mele, M. C., G. Cannelli, G. Carta, L. Cordeddu, M. P. Melis, E. Murru, C. Stanton, and S. Banni. 2013. Metabolism of c9,t11conjugated linoleic acid (CLA) in humans. Prostaglandins Leukot. Essent. Fatty Acids 89:115-119.

Mollica, M. P., G. Trinchese, G. Cavaliere, C. De Filippo, E. Cocca, M. Gaita, A. Della-Gatta, A. Marano, G. Mazzarella, and P. Bergamo. 2014. c9,t11-conjugated linoleic acid ameliorates steatosis by modulating mitochondrial uncoupling and Nrf2 pathway. J. Lipid Res. 55:837-849.

Moraes, M. L., A. M. L. Ribeiro, A. M. Kessler, V. S. Ledur, M. M. Fischer, L. Bockor, and D. Gava. 2012. Effect of CLA on performance and immune response of weanling piglets. J. Anim. Sci. 90:2590-2598.

Nair, S., S. T. Doh, J. Y. Chan, A. N. Kong, and L. Cai. 2008. Regulatory potential for concerted modulation of Nrf2- and Nfkb1mediated gene expression in inflammation and carcinogenesis. Br. J. Cancer 99:2070-2082.

Oliveira, D. E., M. A. S. Gama, D. Fernandes, L. O. Tedeschi, and D. E. Bauman. 2012. An unprotected conjugated linoleic acid supplement decreases milk production and secretion of milk components in grazing dairy ewes. J. Dairy Sci. 95:1437-1446.

Patterson, E., R. Wall, G. F. Fitzgerald, R. P. Ross, and C. Stanton. 2012. Health implications of high dietary omega-6 polyunsaturated fatty acids. J. Nutr. Metab. 2012:539426.

Pires, J. A. A., and R. R. Grummer. 2008. Specific fatty acids as metabolic modulators in the dairy cow. Rev. Bras. Zootec. 37:287-298.

Rahman, I. 2005. Regulation of glutathione in inflammation and chronic lung diseases. Mutat. Res. 579:58-80.

Ramos, K. L., and A. Colquhoun. 2003. Protective role of glucose6-phosphate dehydrogenase activity in the metabolic response of C6 rat glioma cells to polyunsaturated fatty acid exposure. Glia 43:149-166.

Repetto, M., J. Semprine, and A. Boveris. 2012. Lipid peroxidation: Chemical mechanism, biological implications and analytical determination. Chapter 1 in Lipid Peroxidation, A. Catala (Ed.), InTech, Rijeka, Croatia. https://doi.org/10.5772/45943.

Richard, D., K. Kefi, U. Barbe, P. Bausero, and F. Visioli. 2008. Polyunsaturated fatty acids as antioxidanta. Pharmacol. Res. 57:451455.

Rincón-Cervera, M. Á., R. Valenzuela, M. C. Hernandez-Rodas, C. Barrera, A. Espinosa, M. M. Arambio, and A. Valenzuela. 2016. Vegetable oils rich in alpha linolenic acid increment hepatic n-3 LCPUFA, modulating the fatty acid metabolism and antioxidant response in rats. Prostaglandins Leukot. Essent. Fatty Acids https://doi.org/10.1016/j.plefa.2016.02.002.

Schmid, A., M. Collomb, R. Sieber, and G. Bee. 2006. Conjugated linoleic acid in meat and meat products: A review. Meat Sci. $73: 29-41$

Simopoulos, A. P. 2008. The importance of the omega-6/omega-3 fatty acid ratio in cardiovascular disease and other chronic diseases. Exp. Biol. Med. (Maywood) 233:674-688.

Sordillo, L. M., and S. L. Aitken. 2009. Impact of oxidative stress on the health and immune function of dairy cattle. Vet. Immunol. Immunopathol. 128:104-109.

Spector, A. A., and H. Y. Kim. 2015. Discovery of essential fatty acids. J. Lipid Res. 56:11-21.

Zeitz, J. O., E. Most, and K. Eder. 2015. Effect of conjugated linoleic acid on concentrations of fat-soluble vitamins in milk of lactating ewes. J. Dairy Sci. 98:7328-7334. 